Research Article

\title{
Impacts of Air-Sea Energy Transfer on Typhoon Modelling
}

\author{
Difu Sun $\mathbb{D}^{1,2}$ Junqiang Song, ${ }^{1,2}$ Hongze Leng $\mathbb{D}^{1,2}$ Kaijun Ren, ${ }^{1,2}$ and Xiaoyong Li $\mathbb{D}^{1,2}$ \\ ${ }^{1}$ College of Meteorology and Oceanography, National University of Defense Technology, Changsha 410073, China \\ ${ }^{2}$ College of Computer Science and Technology, National University of Defense Technology, Changsha 410073, China
}

Correspondence should be addressed to Hongze Leng; hzleng@nudt.edu.cn

Received 14 January 2021; Revised 17 March 2021; Accepted 5 April 2021; Published 15 April 2021

Academic Editor: Francisco Molero

Copyright $\odot 2021$ Difu Sun et al. This is an open access article distributed under the Creative Commons Attribution License, which permits unrestricted use, distribution, and reproduction in any medium, provided the original work is properly cited.

\begin{abstract}
The Coupled Ocean-Atmosphere-Wave-Sediment Transport model has been used to simulate Super Typhoon Yutu (2018). The impacts of four momentum transfer parameterization schemes (COARE, TY, OT, and DN) and three heat transfer parameterization schemes (COARE, GR, and ZK) on typhoon modelling have been studied by means of the track, intensity, and radial structure of typhoon. The results show that the track of Yutu is not sensitive to the choice of parameterization scheme, while the combinations of different parameterization schemes affect the intensity of Yutu. Among the four momentum flux parameterization schemes, three wave-state-based schemes (TY, OT, and DN) provide better intensity results than the wind-speed-based COARE scheme, but the differences between the three wave-state-based schemes are not obvious. Among the three heat flux parameterization schemes, the results of the GR scheme are slightly better than those of the COARE scheme, and both the GR and COARE schemes are significantly better than the ZK scheme, from which the intensity of Yutu is underpredicted obviously. The influence of the combination of different parameterization schemes on the intensity of the typhoon is also reflected in the radial structure of the typhoon, and the radial structure of the typhoon simulated by experiments with stronger typhoon intensity also develops faster. Differences of intensity between experiments are due mainly to the differences in sea surface heat flux, the enthalpy transferred from sea surface to the atmosphere has a significant impact on the bottom atmosphere wind field, and there is a strong correspondence between the distribution of enthalpy flux and the bottom wind field.
\end{abstract}

\section{Introduction}

Tropical cyclones are one of the most severe weather phenomena, which cause huge loss of lives and property to coastal areas $[1,2]$. Accurate predictions of the track and intensity of tropical cyclones, especially typhoons and hurricanes, are of great significance for reducing hazards of tropical cyclones and emergency management.

Due to the development of numerical forecasting models, typhoon track forecasts have been greatly improved during the past few decades. However, because of the complexity of the internal physical mechanism of typhoons and the difficulty of accurately describing some small-scale processes related to the intensification of typhoon in numerical forecasting models, the improvement of typhoon intensity forecasting is relatively slow [3].

As the energy source of typhoons, the ocean plays an important role in the generation and intensification of typhoons. An accurate description of the energy exchange between the atmosphere and the ocean is essential to the prediction of typhoon intensity [4-7]. In current models, the energy exchange between the atmosphere and the ocean is described by momentum flux and moist enthalpy flux, where the moisture enthalpy flux is the sum of sensible heat flux and latent heat flux. Momentum flux $\tau$, sensible heat flux SHF, and latent heat flux LHF between air and sea can be expressed as

$$
\begin{gathered}
\tau=\rho C_{d} U_{10}^{2}, \\
\mathrm{SHF}=\rho C_{\text {air }} C_{h} U_{10} \Delta \theta, \\
\mathrm{LHF}=\rho L_{\text {vap }} C_{q} U_{10} \Delta q,
\end{gathered}
$$

where $\rho$ is the air density, $U_{10}$ is the wind speed at a height of $10 \mathrm{~m}, C_{\text {air }}$ is the specific heat capacity of air, and $L_{\text {vap }}$ is the latent heat of vaporization, $C_{d}, C_{h}$, and $C_{q}$ are momentum exchange coefficient (also called drag coefficient), sensible 
heat flux exchange coefficient, and latent heat flux exchange coefficient, respectively. In neural stratifications, $C_{d}, C_{h}$, and $C_{q}$ can be calculated from

$$
\begin{aligned}
C_{d} & =\frac{k^{2}}{\left[\ln \left(z_{\text {ref }} / z_{0}\right)\right]^{2}}, \\
C_{h} & =\frac{k^{2}}{\ln \left(z_{\text {ref }} / z_{0}\right) \times \ln \left(z_{\text {ref }} / z_{t}\right)}, \\
C_{q} & =\frac{k^{2}}{\ln \left(z_{\text {ref }} / z_{0}\right) \times \ln \left(z_{\text {ref }} / z_{q}\right)},
\end{aligned}
$$

where $k=0.4$ is the Von Kármán constant, $z_{\text {ref }}$ is the reference height, often taken as $10 \mathrm{~m}, z_{0}, z_{t}$, and $z_{q}$ are the roughness length for momentum, sensible heat, and water vapor, respectively.

For the calculation of momentum flux, early applications treated $C_{d}$ or $z_{0}$ as a function of wind speed. In low and moderate wind conditions $\left(U_{10} \leq 20 \mathrm{~m} / \mathrm{s}\right)$, many observations show that $C_{d}$ increases linearly with wind speed [8-10]. Therefore, the function of $C_{d}$ in low and moderate wind conditions can be expressed as

$$
10^{3} C_{d}=a+b U_{10}
$$

From different observations, the coefficients $a$ and $b$ are fitted to different values (Table 1 ). It can be seen that the functions of $C_{d}$ fitted by different observations all reveal the monotonically increasing relationship of $C_{d}$ with $U_{10}$, but the values of coefficients $a$ and $b$ differ significantly. The difference indicates that $C_{d}$ may not only depend on wind speed. Many studies have shown that wave state has an important influence on the surface roughness $[11,12]$.

Due to the lack of observations under high wind speed conditions, in some early models [21, 22], the linear relation between $C_{d}$ and $U_{10}$ is extrapolated to high wind speed conditions. However, some recent field experiments and laboratory experiments show that when the wind speed reaches a certain level, $C_{d}$ no longer increases with the increase of $U_{10}$, but reaches a saturation value $[23,24]$, or decreases with the increase of $U_{10}$ [25]. This $C_{d}$ saturation effect is related to the wave breaking and the generation of sea foam under high wind speeds $[26,27]$. Due to the important influence of wave state on momentum transfer, many wavestate-based sea surface roughness parameterization schemes have been proposed to calculate the momentum flux between air and sea, such as the wave-steepness-based $z_{0}$ parameterization scheme proposed by Taylor and Yelland [28] (equation (8)) and the wave-age-based scheme proposed by Drennan et al. [29] (equation (9)):

$$
\begin{aligned}
& \frac{z_{0}}{H_{s}}=1.2 \times 10^{2}\left(\frac{H_{s}}{L_{p}}\right)^{4.5}, \\
& \frac{z_{0}}{H_{s}}=3.35 \times\left(\frac{c_{p}}{u_{*}}\right)^{-3.4},
\end{aligned}
$$

TABle 1: Coefficients $a$ and $b$ in (7) from various observations.

\begin{tabular}{lcc}
\hline Reference & $a$ & $b$ \\
\hline Kondo [13] & 1.20 & 0.025 \\
Wu [14] & 0.80 & 0.065 \\
Large and Pond [15] & 0.49 & 0.065 \\
Donelan [16] & 0.96 & 0.041 \\
Geernaert et al. [9] & 0.58 & 0.085 \\
Vickers and Mahrt [17] & 0.75 & 0.067 \\
Drennan et al. [18] & 0.60 & 0.070 \\
Guan and Xie [19] & 0.78 & 0.065 \\
Toffoli et al. [20] & 0.96 & 0.060 \\
\hline
\end{tabular}

where $H_{s}$ is the significant wave height, $L_{p}$ is the wave length at the spectral peak, $H_{s} / L_{p}$ denotes the wave steepness, $c_{p}$ is the wave speed at the spectral peak, $u_{*}$ is the friction velocity, and $c_{p} / u_{*}$ denotes the wave age. Compared with the scheme based on wind speed, schemes based on wave state describe the physical state of the sea surface more directly and are often used in the atmosphere-ocean-wave coupling model, in which the wave state is provided by the ocean model or the wave model.

The heat transported from ocean to atmosphere is the main energy source for typhoon $[30,31]$. Due to the difficulties in measuring heat flux directly, the mechanism of airsea heat transfer is relatively dubious. According to the method adopted, the parameterization schemes of heat flux can be roughly divided into the following categories: (1) based on the observations in low and moderate wind conditions, sensible heat flux exchange coefficient $C_{h}$ and latent heat flux exchange coefficient $C_{q}$ are treated as a constant [32]; (2) by fitting observations directly to dimensionless parameters, such as roughness Reynolds number $R_{r}$, the sensible heat roughness $z_{t}$ and water vapor roughness $z_{q}$ can be denoted as a function of dimensionless parameters [33]; (3) describe the ratio between $z_{t}$ or $z_{q}$ and $z_{0}$ as a function of roughness Reynolds number $R_{r}$ and Prandtl number $P_{r}: z_{t, q}=f\left(R_{r}, P_{r}\right)$ [34]. As mentioned above, there are differences between different heat flux parameterization schemes, which will lead to differences in the typhoon modelling results.

This study aims to improve the understanding of the influence of air-sea energy exchange on typhoon modelling, especially the influence on intensity forecast. To examine the impact of momentum flux and heat flux on typhoon intensity, we evaluated the performance of four momentum flux parameterization schemes and three heat flux parameterization schemes in the simulation of Super Typhoon Yutu.

\section{Methods}

2.1. Momentum Flux Parameterization Schemes. In the numerical model, the momentum flux of the sea surface is determined by the drag coefficient $C_{d}$ (equation (1)), and $C_{d}$ can be calculated from $z_{0}$ (equation (4)). Therefore, different momentum flux parameterization schemes in the model are realized by different calculation schemes for $z_{0}$. 
2.1.1. COARE. COARE (Coupled Ocean-Atmosphere Response Experiment) scheme was proposed based on the flux measurements collected from the TOGA (Tropical Ocean Global Atmosphere) COARE experiment [35], which is widely used in flux calculations in various numerical models $[36,37]$; here we adopt the v3.5 version of COARE proposed by Edson et al. [10].

COARE divides $z_{0}$ into two parts:

$$
z_{0}=z_{0}^{\text {smooth }}+z_{0}^{\text {rough }}
$$

where $z_{0}^{\text {smooth }}$ represents the roughness corresponding to the part of the momentum transported entirely by the viscous effect of the sea surface when the sea surface is flat; in addition to the momentum transfer caused by the viscous effect, due to the actual unevenness of the sea surface, the wind produces horizontal wind pressure on the sea surface, which causes the horizontal momentum to be transferred to waves, and this part of the momentum transfer corresponds to roughness $z_{0}^{\text {rough }} . z_{0}^{\text {smooth }}$ is calculated from

$$
z_{0}^{\text {smooth }}=\gamma \frac{v}{u_{*}}
$$

where $\nu$ is the kinematic viscosity of air and $\gamma$ is taken as 0.11 by COARE from observations. $z_{0}^{\text {rough }}$ is often calculated from Charnock relation [38]:

$$
z_{0}^{\text {rough }}=\alpha \frac{u_{*}^{2}}{g},
$$

where $\alpha$ is the Charnock coefficient and $g$ is the gravitational acceleration. Then, (10) is written as

$$
z_{0}=\gamma \frac{\nu}{u_{*}}+\alpha \frac{u_{*}^{2}}{g} .
$$

Charnock coefficient $\alpha$ is denoted as a function of wind speed by COARE based on observations:

$$
\alpha=m U_{10}+b,
$$

where $m=0.017 \mathrm{~m}^{-1} \mathrm{~s}$ and $b=-0.005$.

2.1.2. TY. Based on the observations from HEXOS (the Humidity Exchange over the Sea) [39], RASEX (the Risø Air-Sea Exchange) [40], and Lake Ontario [41] experiments, Taylor and Yelland [28] proposed a sea surface roughness parameterization scheme considering significant wave height $H_{s}$ and wave steepness $H_{s} / L_{p}$ :

$$
\frac{z_{0}}{H_{s}}=1200\left(\frac{H_{s}}{L_{p}}\right)^{4.5} .
$$

Compared with the wind-speed-based COARE scheme, TY scheme describes the relationship between the physical properties of the sea surface and $z_{0}$ more directly.

2.1.3. OT. From the momentum flux observations collected from ASGMAGE (an union of ASGASEX (Air Sea GAS
EXchange) and MAGE (Marine Aerosol and Gas Exchange)) experiment, Oost et al. [42] proposed a scheme considering wave length $L_{p}$ and wave age $c_{p} / u_{*}$ :

$$
\frac{z_{0}}{L_{p}}=\frac{25}{\pi}\left(\frac{u_{*}}{c_{p}}\right)^{4.5},
$$

Wave age $c_{p} / u_{*}$ represents the relative magnitude of wave speed and wind speed, and the ability of winds to transfer momentum to waves.

2.1.4. DN. By filtering out momentum flux data from the pure wind wave field and deep water conditions from AGILE (measured from the 15-m research vessel AGILE) [43], FETCH (Flux, sea state, and remote sensing in conditions of variable fetch) [44], HEXOS, SWADE (Surface Waves Dynamics Experiment) [45], and WAVES (Water-Air Vertical Exchange Study) [46] experiments, Drennan et al. [29] proposed a scheme considering wave age $c_{p} / u_{*}$ :

$$
\frac{z_{0}}{H_{s}}=3.35\left(\frac{u_{*}}{c_{p}}\right)^{3.4} .
$$

Among the above four schemes, except for the COARE scheme, which uses wind speed to calculate $z_{0}$, the other three schemes are all based on wave parameters. Since the atmospheric model generally does not directly provide wave parameters, TY, OT, and DN schemes are mainly used in the coupled model, in which the wave parameters can be provided by wave model.

\subsection{Heat Flux Parameterization Schemes}

2.2.1. COARE. In addition to the calculation scheme of $z_{0}$, COARE also provides the calculation scheme of $z_{t}$ and $z_{q}$. In COARE scheme, $z_{t}$ and $z_{q}$ are taken as the same value:

$$
z_{t}=z_{q}=\min \left(1.6 \times 10^{-4}, 5.5 \times 10^{-5} R_{r}^{-0.6}\right),
$$

where $R_{r}=z_{0} u_{*} / v$ is the roughness Reynolds number.

2.2.2. GR. GR scheme proposed by Garratt [47] calculate $z_{t}$ and $z_{q}$ from $z_{0}$ and $R_{r}$; values of $z_{t}$ and $z_{q}$ are slightly different:

$$
\begin{aligned}
& z_{t}=z_{0} \exp \left(2-2.48\left(R_{r}^{1 / 4}\right)\right) \\
& z_{q}=z_{0} \exp \left(2-2.28\left(R_{r}^{1 / 4}\right)\right)
\end{aligned}
$$

2.2.3. ZK. Based on the observations from TOGA COARE and SCOPE (San Clemente Ocean Probing Experiment) [48], Zilitinkevich et al. [34] proposed a scheme to calculate $z_{t}$ and $z_{q}$ in different sea surface roughness conditions: 


$$
\begin{aligned}
& z_{t}=\left\{\begin{array}{ll}
z_{0} \exp (k \times 2.0), & R_{r}<0.1 \\
z_{0} \exp \left(-k \times\left(4.0 R_{r}^{1 / 2}-3.2\right)\right), & R_{r} \geq 0.1
\end{array},\right. \\
& z_{q}= \begin{cases}z_{0} \exp (k \times 3.0), & R_{r}<0.1 \\
z_{0} \exp \left(-k \times\left(4.0 R_{r}^{1 / 2}-4.2\right)\right), & R_{r} \geq 0.1\end{cases}
\end{aligned}
$$

$R_{r}=0.1$ is chosen as the threshold value because the fitting curves of observational data match the curves of smooth regime equations at that point.

2.3. Evaluation Parameters. To quantitatively compare the results of the typhoon simulations, we introduced three parameters to evaluate the simulation results: the root mean square error (RMSE), Pearson correlation coefficient $(R)$, and model skill $(S)$, given as

$$
\begin{aligned}
\mathrm{RMSE} & =\sqrt{\frac{1}{N} \sum_{i=1}^{N}\left(y_{i}-x_{i}\right)^{2}} \\
R & =\frac{\sum_{i=1}^{N}\left(y_{i}-\bar{y}\right)\left(x_{i}-\bar{x}\right)}{\sqrt{\sum_{i=1}^{N}\left(x_{i}-\bar{x}\right)^{2}} \sqrt{\sum_{i=1}^{N}\left(y_{i}-\bar{y}\right)^{2}}} \\
S & =1-\frac{\sum_{i=1}^{N}\left|y_{i}-x_{i}\right|^{2}}{\sum_{i=1}^{N}\left(\left|y_{i}-\bar{x}\right|^{2}+\left|x_{i}-\bar{x}\right|^{2}\right)}
\end{aligned}
$$

where $x_{i}$ and $y_{i}$ represent the observed and simulated values, respectively, with respect to time.

\section{Case Introduction and Experimental Design}

3.1. An Overview of Super Typhoon Yutu. Super Typhoon Yutu is the 26th named tropical cyclone in the Western North Pacific in 2018. At 1200 UTC 21 Oct 2018, Yutu formed as a tropical depression on the tropical ocean near $158^{\circ} \mathrm{E}$ and $8^{\circ} \mathrm{N}$, it upgraded to a tropical storm at $0000 \mathrm{UTC}$ $22 \mathrm{Oct}$, and then it reached the intensity of typhoon at 0000 UTC 23 Oct. At 2000 UTC 24 Oct, its intensity exceeded the Super Typhoon Mangkhut (22nd named tropical cyclone in the Northwest Pacific in 2018) and thus became the strongest tropical cyclone in 2018. Figure 1 shows the track and intensity changes of Yutu from the Best-Track data released by the JTWC (Joint Typhoon Warning Center).

3.2. Experimental Design. Experiments in this study are conducted on the COAWST (Coupled Ocean-AtmosphereWave-Sediment Transport) [49] model. Super Typhoon Yutu is simulated in the atmospheric model, and wave model is activated to provide wave parameters to atmospheric model for the calculation of $z_{0}$, because the activation of ocean model will cause a cold deviation of the sea surface temperature in the simulation of tropical cyclones over the Western North Pacific [50], and the ocean model was not activated in our experiments.

Weather Research and Forecasting (WRF-ARW 4.1.5) model is the atmospheric model used in the coupled model.

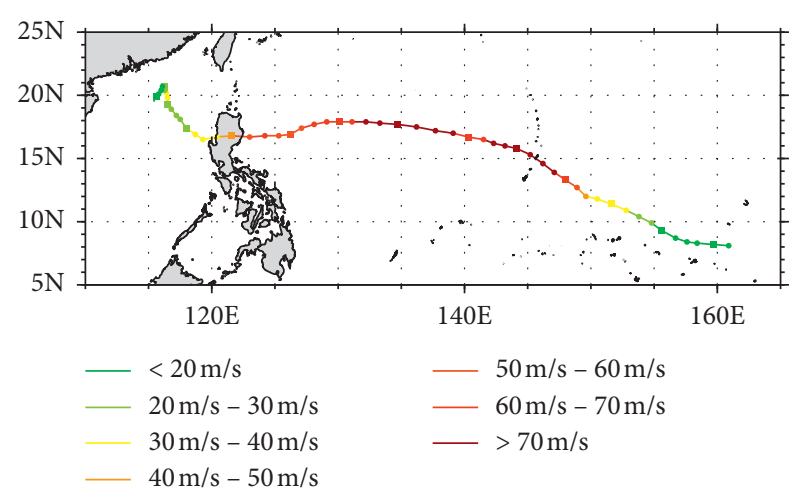

Figure 1: Intensity and track of Yutu from JTWC Best-Track data between 1800 UTC 20 Oct 2018 and 0600 UTC 3 Nov 2018. Positions at 0000 UTC are marked by squares, and the colors of the track indicate the maximum wind speed at $10 \mathrm{~m}$ level above the sea surface.

6-hourly $0.25^{\circ} \times 0.25^{\circ}$ GDAS (Global Data Assimilation System) Final Analysis data from NCEP (National Centers for Environmental Prediction) were used as the initial and boundary conditions. There are three two-way nested grids in the present work-D01, D02, and D03 (Figure 2). The outermost grid D01 has a horizontal spacing of $27 \mathrm{~km}$ and a time step of $90 \mathrm{~s}$; the second grid D02 has a horizontal spacing of $9 \mathrm{~km}$ and a time step of $30 \mathrm{~s}$; the innermost grid D03 is a vortex following grid moving along the typhoon center, the vortex is tracked at $500 \mathrm{hPa}$ level, its position is calculated every 15 minutes, and the max vortex speed is taken as $40 \mathrm{~m} / \mathrm{s}$ for the calculation of the new vortex center position; its initial position is drawn as the red box in Figure 2, the horizontal spacing of D03 is $3 \mathrm{~km}$, and its time step is $10 \mathrm{~s}$. A total of 44 vertical layers with a pressure top of $10 \mathrm{hPa}$ are adopted. Purdue Lin's [51] scheme is used as the microphysics scheme; both shortwave and longwave radiation are resolved by Rapid Radiative Transfer Model for Global Circulation Models (RRTMG) [52], Mellor-Yamada Nakanishi and Niino level 2.5 (MYNN) [53] is adopted as the planetary boundary layer scheme, surface layer model is MYNN, land surface model is set to Unified Noah [54], and Kain-Fritsch [55] cumulus scheme is only activated in D01 and D02.

Wave parameters needed $\left(H_{s}, L_{p}\right.$, and $\left.c_{p}\right)$ in the calculation of $z_{0}$ are calculated by wave model SWAN (Simulating Waves Nearshore, 41.31) and are transferred to WRF through the coupler MCT (Model Coupling Toolkit); SWAN model also receives the $10 \mathrm{~m}$ wind field from WRF as the forcing field. Horizontal spacing of SWAN is about $9 \mathrm{~km}$, and the time step is $180 \mathrm{~s}$; the domain of SWAN is shown as the blue box in Figure 2 .

Both atmospheric and wave model are initialized at 1200 UTC 22 Oct 2018 and are integrated for 5 days to 1200 UTC 27 Oct 2018. The simulation period covers the entire enhancement process of Yutu; in this period, track of Yutu is all over the sea, and the influence of different parameterization schemes on the momentum and heat transfer between ocean and typhoon can be fully analysed. 


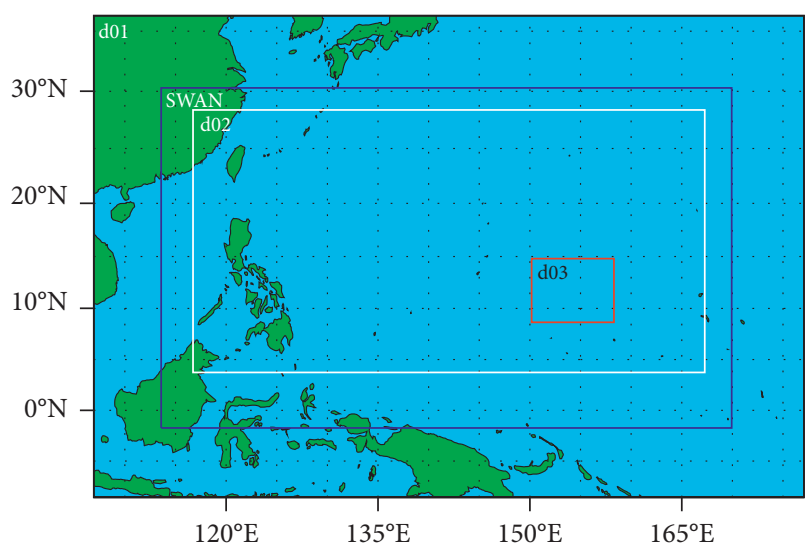

Figure 2: Model domains configuration. The outermost is the domain of D01, the white box represents the domain of D02, the red box represents the initial position of vertex-following nest D03, and the blue box represents the domain of SWAN.

There are 12 experiments in this study: four momentum flux parameterization schemes and three heat flux parameterization schemes described in Section 2 are called pairwise. Except for the flux parameterization scheme, other settings are all the same. The parameterization schemes used in each group of experiments are summarized in Table 2.

\section{Results and Discussion}

4.1. Track and Intensity. Comparison between simulated tracks of Yutu and Best-Track data is plotted in Figure 3. Overall, the movement of typhoon from the southeast to the northwest is reproduced by every experiment, but the simulated moving speeds are slower than that of the Best-Track data. Differences of tracks between 12 experiments are not obvious, and the tracks of Yutu before 0000 UTC 25 Oct from 12 experiments are generally the same. In general, simulated tracks of Yutu are not sensitive to the flux parameterization schemes, which is in agreement with many typhoon simulation studies $[3,56]$, because typhoon track is mainly affected by the large-scale steering flow, while the small-scale flux transport has limited impact on it.

Comparisons between simulated intensities and Best-Track data are shown in Figure 4. Results of MSLP (minimum sea level pressure) are plotted in Figure 4(a). From the Best-Track data, we can see that Yutu intensified rapidly during $12-48 \mathrm{~h}$ of the simulation period, and its MSLP reduced by about $80 \mathrm{hPa}$, but this rapid intensification process has not been reproduced well by experiments; the reduction speeds of simulated MSLP are slower than that of Best-Track data. Although the mechanism of the rapid intensification of tropical cyclone is still controversial [57], it is widely accepted that the thermodynamic and kinematic properties of the TC core play an important role in rapid intensification $[58,59]$. In the numerical simulations, how the model calculates convective process matters a lot for the rapid intensification of TC. Hence, the failure in reproducing the rapid intensification of Yutu may be due to the inability of the current convection calculation
TABLE 2: Parameterization schemes of momentum and heat flux in 12 experiments.

\begin{tabular}{lccc}
\hline EXP ID & EXP name & Momentum flux scheme & Heat flux scheme \\
\hline 1 & CR_CR & COARE & COARE \\
2 & CR_GR & COARE & GR \\
3 & CR_ZK & COARE & ZK \\
4 & TY_CR & TY & COARE \\
5 & TY_GR & TY & GR \\
6 & TY_ZK & TY & ZK \\
7 & OT_CR & OT & COARE \\
8 & OT_GR & OT & GR \\
9 & OT_ZK & OT & ZK \\
10 & DN_CR & DN & COARE \\
11 & DN_GR & DN & GR \\
12 & DN_ZK & DN & ZK \\
\hline
\end{tabular}

scheme to reproduce the convection processes in the TC core. Results simulated by different experiments differ a lot; MSLP from four experiments using $\mathrm{ZK}$ scheme as the heat flux parameterization scheme (CR_ZK, TY_ZK, OT_ZK, and DN_ZK) is much larger than others, which denotes the typhoon intensities are affected by the adoptions of ZK scheme. The performances of COARE, GR, and ZK schemes in numerical simulations have also been evaluated by Bao et al. [4] using the National Atmospheric and Oceanic Administration/ Environmental Technology Laboratory (NOAA/ETL) regional air-sea coupled modelling system, from their results (Figure 1 in Bao et al. [4]). ZK scheme showed the worst performances, hurricane simulated by ZK scheme did not intensify at all, and GR scheme was slightly better than COARE scheme. Due to the different MSLP reduction speeds simulated by different experiments, the simulation results of MSLP showed a big difference at $120 \mathrm{~h}$ : the smallest is about $900 \mathrm{hPa}$ (DN_CR) and the largest is about $940 \mathrm{hPa}$ (CR_ZK); the difference exceeds $40 \mathrm{hPa}$.

Figure 4(b) presents the results of UMAX (maximum wind speed at $10 \mathrm{~m}$ level); the increasing trend of UMAX corresponds to the decreasing trend of MSLP, the rapid increasing of UMAX during $12-48 \mathrm{~h}$ is also not reproduced well by experiments, and UMAX simulated by the four experiments using ZK scheme as the heat flux parameterization scheme also showed obvious weak deviations.

Listed in Table 3 are the RMSE, Pearson correlation coefficient, and model skill of simulated MSLP from 12 experiments. Among the 12 experiments, RMSE of TY_CR is the smallest $(17.30 \mathrm{hPa})$, and the largest is that of CR_ZK $(34.49 \mathrm{hPa})$. The difference in Pearson correlation coefficient between different experiments is not obvious. The model skill also shows significant differences: the highest is TY_CR (0.8447) and the lowest is CR_ZK (0.4198), which is consistent with the results of RMSE.

To compare the performances of different parameterization schemes on MSLP simulation more intuitively, Table 4 lists the average RMSE, R, and S of experiments that use the same schemes. From the results of four momentum flux parameterization schemes, it can be seen that the performance of wave -state-based TY, OT, and DN schemes is generally better than the wind-speed-based COARE scheme. 


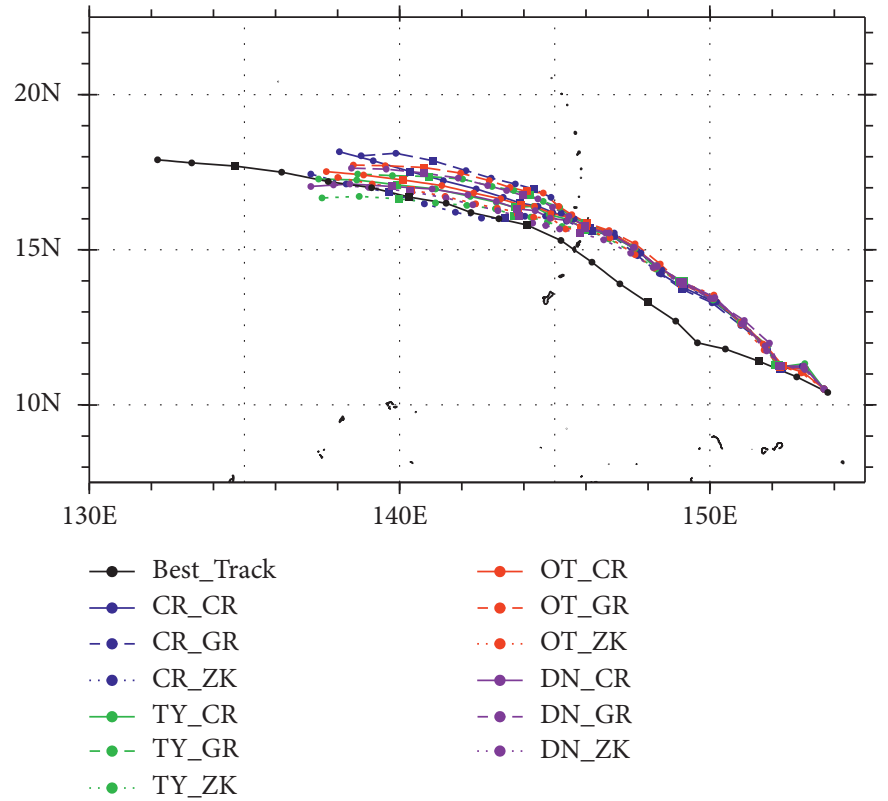

(a)

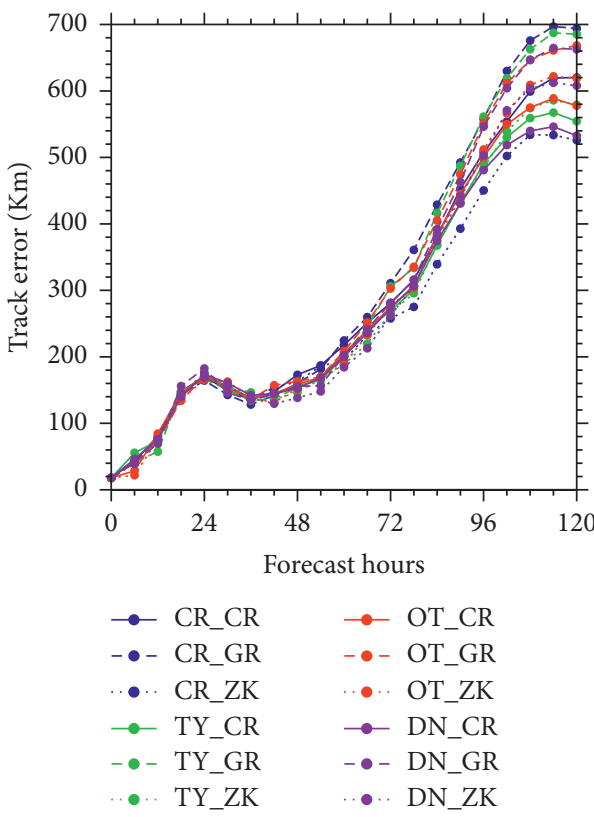

(b)

FIGURE 3: Simulated (a) tracks between 1200 UTC 22 Oct 2018 and 1200 UTC 27 Oct 2018 (positions at 0000 UTC are marked by squares) and (b) track errors from different experiments.

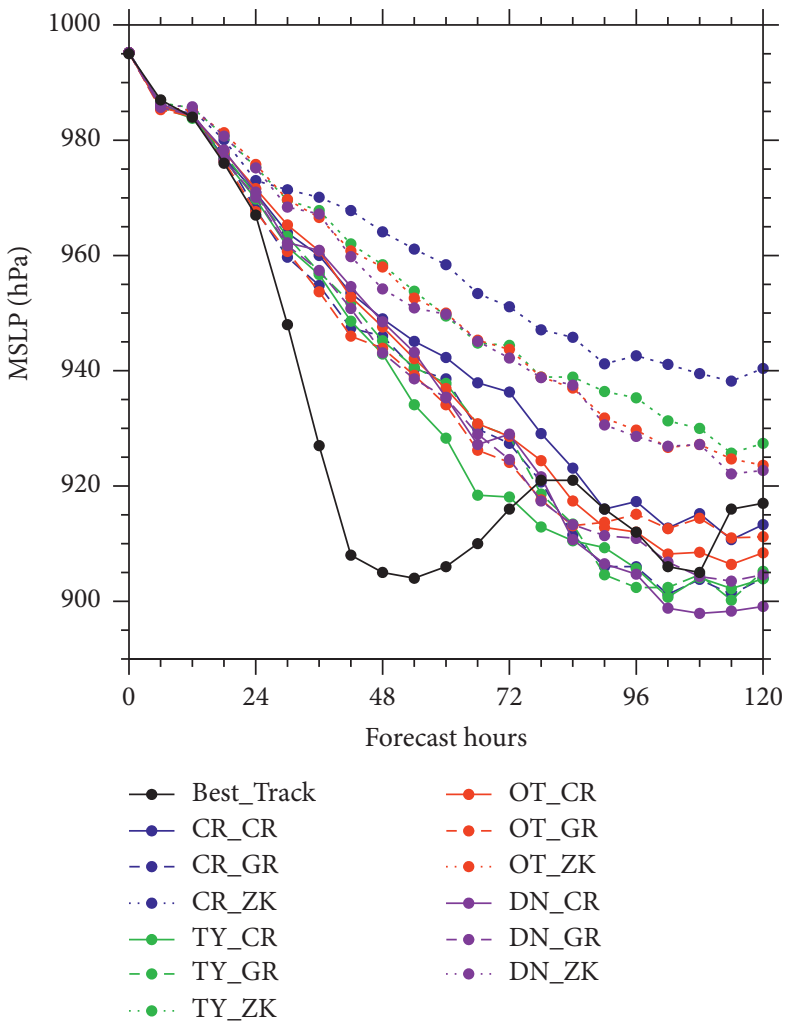

(a)

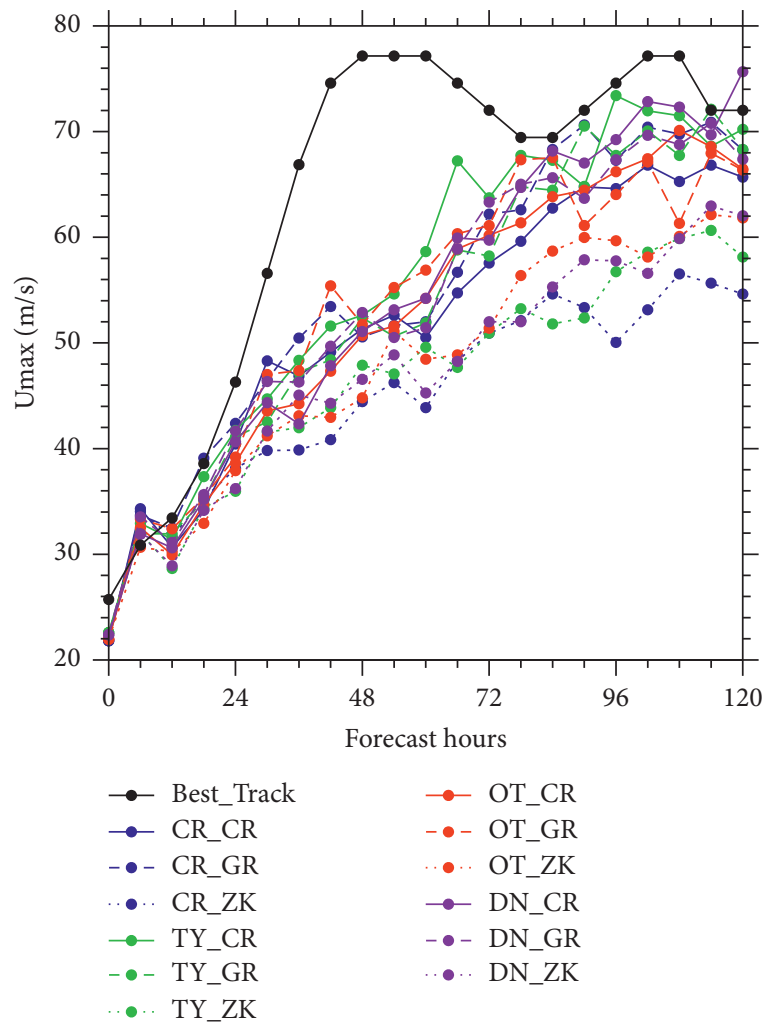

(b)

Figure 4: Comparison between Yutu's JTWC Best-Track data and simulated intensities (a) for minimum sea level pressure and (b) for maximum wind speed at $10 \mathrm{~m}$ level above the sea surface. 
TABLE 3: Root mean square error (RMSE), Pearson correlation coefficient (R), and model skill (S) for MSLP from 12 experiments.

\begin{tabular}{lccr}
\hline EXP name & RMSE $(\mathrm{hPa})$ & $\mathrm{R}$ & $\mathrm{S}$ \\
\hline CR_CR & 21.66 & 0.8378 & 0.7461 \\
CR_GR & 19.14 & 0.8340 & 0.8077 \\
CR_ZK & 34.49 & 0.8241 & 0.4198 \\
TY_CR & 17.30 & 0.8603 & 0.8447 \\
TY_GR & 19.90 & 0.8243 & 0.7956 \\
TY_ZK & 28.83 & 0.8449 & 0.5661 \\
OT_CR & 20.13 & 0.8390 & 0.7838 \\
OT_GR & 17.55 & 0.8740 & 0.8259 \\
OT_ZK & 27.81 & 0.8361 & 0.5938 \\
DN_CR & 21.03 & 0.8065 & 0.7802 \\
DN_GR & 18.65 & 0.8470 & 0.8145 \\
DN_ZK & 27.03 & 0.8441 & 0.6125 \\
\hline
\end{tabular}

TABle 4: Averaged root mean square error (RMSE), Pearson correlation coefficient (R), and model skill (S) for MSLP from different schemes.

\begin{tabular}{lrr}
\hline Group & RMSE (hPa) & R \\
\hline COARE momentum flux scheme group averaged (CR_CR, CR_GR, and CR_ZK) & 25.10 & 0.8320 \\
TY momentum flux scheme group averaged (TY_CR, TY_GR, and TY_ZK) & 22.01 & 0.6564 \\
OT momentum flux scheme group averaged (OT_CR, OT_GR, and OT_ZK) & 21.83 & 0.8432 \\
DN momentum flux scheme group averaged (DN_CR, DN_GR, and DN_ZK) & 22.24 & 0.8497 \\
COARE heat flux scheme group averaged (CR_CR, TY_CR, OT_CR, and DN_CR) & 20.03 & 0.8325 \\
GR heat flux scheme group averaged (CR_GR, TY_GR, OT_GR, and DN_GR) & 18.81 & 0.7345 \\
ZK heat flux scheme group averaged (CR_ZK, TY_ZK, OT_ZK, and DN_ZK) & 29.54 & 0.8448 \\
\hline
\end{tabular}

Compared with the COARE scheme, RMSE of MSLP simulated by three wave-state-based momentum flux parameterization schemes is reduced by about $3 \mathrm{hPa}$ on average. COARE is one of the best wind-speed-based $z_{0}$ parameterization schemes, which has been widely used in momentum flux calculations $[60,61]$; the better results from wave-state-based schemes reveal that the characteristics of momentum flux at typhoon condition are better captured by the wave-state-based schemes; this denotes that considering the impacts of wave state can provide more information for the parameterization of $z_{0}$. Similar conclusions are presented by Drennan et al. [62] and Prakash et al. [63]. From the results of three heat flux parameterization schemes, it is demonstrated that the MSLP results simulated by the ZK scheme are worse than the other two schemes. The MSLP RMSE is significantly higher, and the model skill is significantly lower. Results of the GR scheme are slightly better than the COARE scheme. The relative performances of three heat flux parameterization schemes are consistent with Bao et al. [4].

RMSE, Pearson correlation coefficient, and model skill of simulated UMAX from 12 experiments are given in Table 5. Among 12 experiments, RMSE of TY_CR is the smallest $(11.47 \mathrm{~m} / \mathrm{s})$, and the largest is that of CR_ZK $(21.35 \mathrm{~m} / \mathrm{s})$. Results of model skill are similar to RMSE; the highest is TY_CR (0.7725), and the lowest is CR_ZK (0.3624). Table 6 lists the group averaged root mean square error (RMSE), Pearson correlation coefficient $(R)$, and model skill $(S)$. From the results of four momentum flux parameterization schemes, it can be seen that the performance of wave-state-
TABle 5: Root mean square error (RMSE), Pearson correlation coefficient $(R)$, and model skill $(S)$ for UMAX from 12 experiments.

\begin{tabular}{lccc}
\hline EXP name & RMSE $(\mathrm{m} / \mathrm{s})$ & $R$ & $S$ \\
\hline CR_CR & 14.67 & 0.8724 & 0.6465 \\
CR_GR & 12.88 & 0.8480 & 0.7094 \\
CR_ZK & 21.35 & 0.8383 & 0.3624 \\
TY_CR & 11.47 & 0.8803 & 0.7725 \\
TY_GR & 13.74 & 0.8440 & 0.6870 \\
TY_ZK & 19.37 & 0.8847 & 0.4562 \\
OT_CR & 14.15 & 0.8668 & 0.6737 \\
OT_GR & 12.76 & 0.8996 & 0.7149 \\
OT_ZK & 18.36 & 0.8524 & 0.4999 \\
DN_CR & 13.49 & 0.8337 & 0.7064 \\
DN_GR & 13.43 & 0.8545 & 0.6928 \\
DN_ZK & 18.91 & 0.8580 & 0.4743 \\
\hline
\end{tabular}

based schemes (TY, OT, and DN) is generally better than the wind-speed-based scheme (COARE), which are consistent with the results in Table 4. RMSE of UMAX simulated by TY, $\mathrm{OT}$, and DN is $1.2 \mathrm{~m} / \mathrm{s}$ smaller than COARE on average. By comparing the results of COARE, GR, and ZK, it is demonstrated that the UMAX results simulated by the $\mathrm{ZK}$ scheme are worse than the other two schemes; results of the GR scheme are slightly better than the COARE scheme.

4.2. Time Evolution of Radial Structure. To analyse the time evolution of the typhoon radial structure, the Hovmöller diagrams of azimuthally averaged SLP (sea level pressure) and $U_{10}$ are plotted in Figures 5 and 6, respectively. The 
TABle 6: Averaged root mean square error (RMSE), Pearson correlation coefficient $(R)$, and model skill $(S)$ for UMAX from different schemes.

\begin{tabular}{lrr}
\hline Group & RMSE (m/s) & $R$ \\
\hline COARE momentum flux scheme group averaged (CR_CR, CR_GR, and CR_ZK) & 16.30 & 0.8529 \\
TY momentum flux scheme group averaged (TY_CR, TY_GR, and TY_ZK) & 14.86 & 0.5728 \\
OT momentum flux scheme group averaged (OT_CR, OT_GR, and OT_ZK) & 15.09 & 0.8697 \\
DN momentum flux scheme group averaged (DN_CR, DN_GR, and DN_ZK) & 15.27 & 0.8729 \\
COARE heat flux scheme group averaged (CR_CR, TY_CR, OT_CR, and DN_CR) & 13.45 & 0.8487 \\
GR heat flux scheme group averaged (CR_GR, TY_GR, OT_GR, and DN_GR) & 13.20 & 0.6295 \\
ZK heat flux scheme group averaged (CR_ZK, TY_ZK, OT_ZK, and DN_ZK) & 19.50 & 0.6245 \\
\hline
\end{tabular}

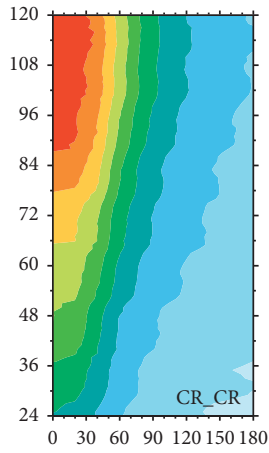

(a)

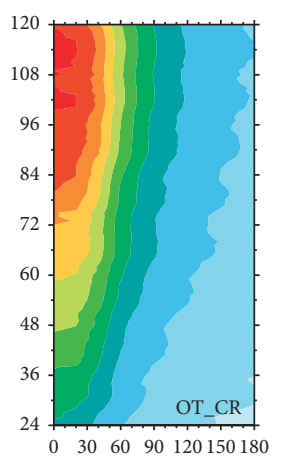

(g)

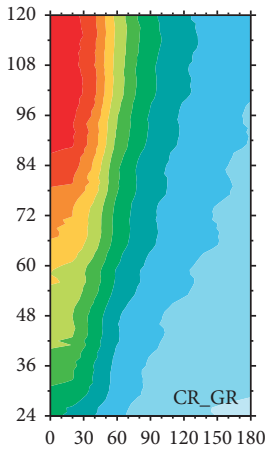

(b)

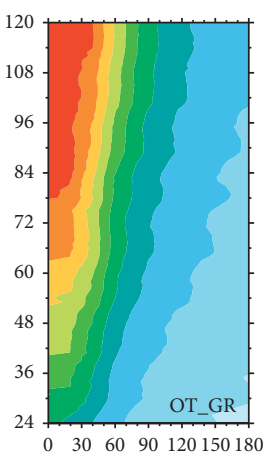

(h)

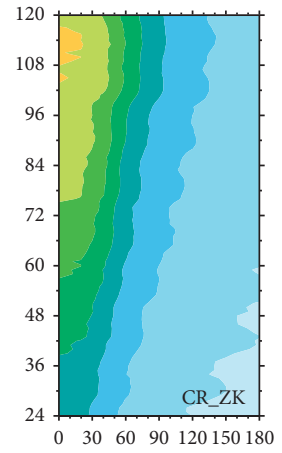

(c)

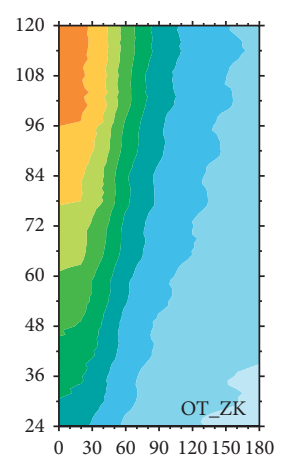

(i)

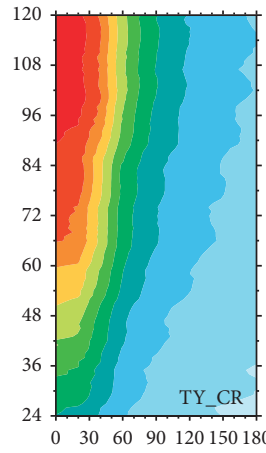

(d)

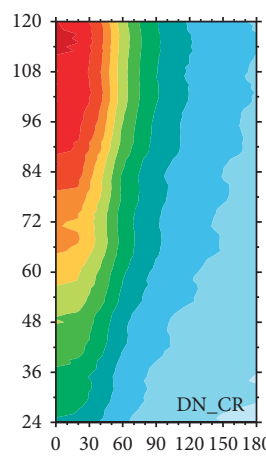

(j)

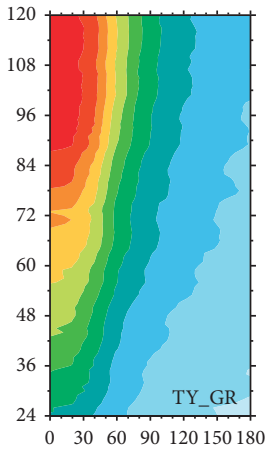

(e)

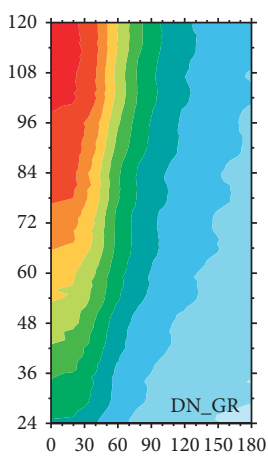

(k)

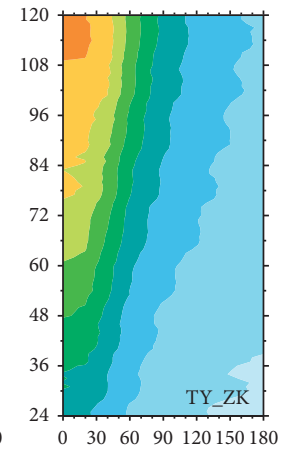

(f)

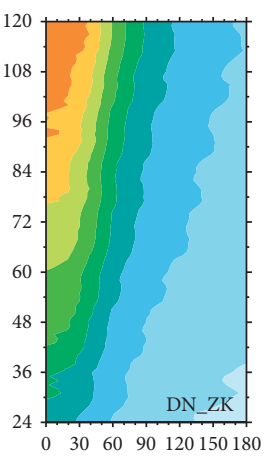

(1)

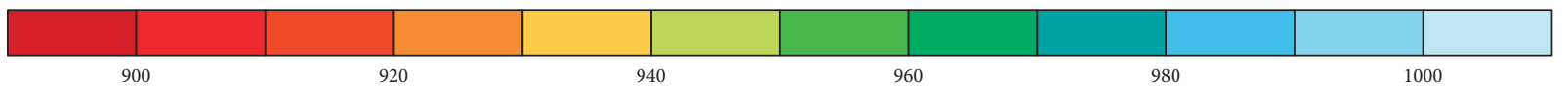

FiguRE 5: Hovmöller diagrams of azimuthally averaged sea level pressure (hPa) from 12 experiments. $x$-axis denotes the distance (km) from the center of the typhoon and $y$-axis denotes the forecast hours.

intensification and the structure development of typhoon are presented in Figure 5; results in Figure 5 are consistent with the results in section 4.1, and experiments using $\mathrm{ZK}$ as the heat flux parameterization scheme tend to underestimate the intensity of Yutu. The faster the typhoon intensifies, the faster the radial pressure gradient increases. Here we take CR_ZK (Figure 5(c)) and TY_CR (Figure 5(d)) as examples. Typhoon simulated by TY_CR intensifies rapidly; it takes $42 \mathrm{~h}$ for TY_CR to intensify to $950 \mathrm{hPa}$, while typhoon simulated by CR_ZK intensifies slower, and it takes about $75 \mathrm{~h}$ for CR_ZK to intensify to $950 \mathrm{hPa}$; in addition to the difference in the speed of the central pressure drop, the development speed of their radial structure is also significantly different. At $72 \mathrm{~h}$, the $980 \mathrm{hPa}$ isobar of CR_ZK is located about $70 \mathrm{~km}$ from the center of typhoon, while the
$980 \mathrm{hPa}$ isobar of TY_CR is located about $90 \mathrm{~km}$ from the center of typhoon, indicating that the radial structure simulated by TY_CR is stronger. It is worth mentioning that typhoon structure simulated by the four experiments that use the ZK heat flux parameterization scheme (CR_ZK (Figure 5(c)), TY_ZK (Figure 5(f)), OT_ZK (Figure 5(j)), and DN_ZK (Figure 5(l)) is not sufficiently developed, which is consistent with the results in Section 4.1.

Figure 6 shows the time evolution of azimuthally averaged tangential winds and radial winds. It can be seen that the wind speeds are relatively small near the center and reaches the maximum value as radius increases and then decreases with radius. The values of tangential winds can reach to more than $50 \mathrm{~m} / \mathrm{s}$, while the maximum value of radial winds is only $25-30 \mathrm{~m} / \mathrm{s}$, indicating that the bottom 


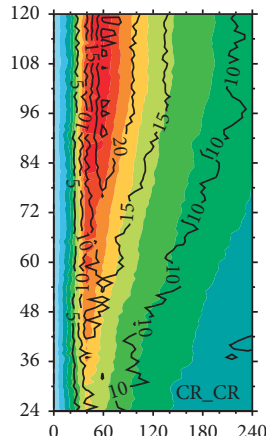

(a)

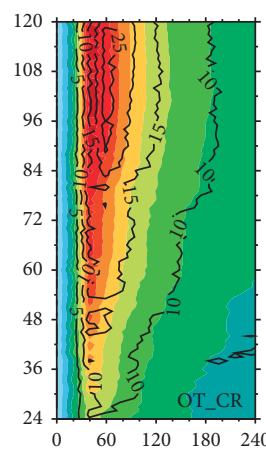

(g)

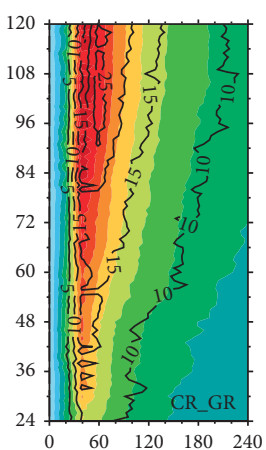

(b)

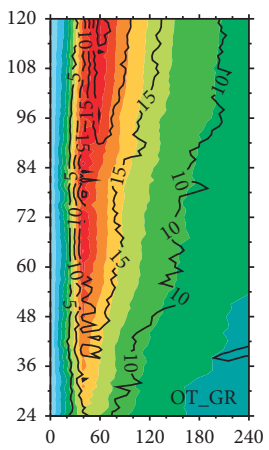

(h)

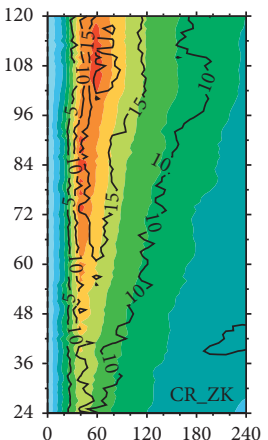

(c)

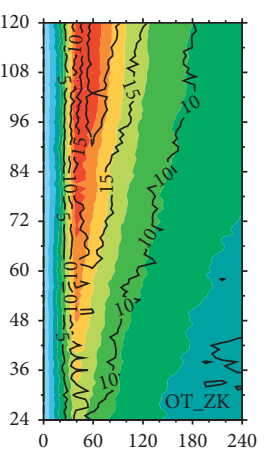

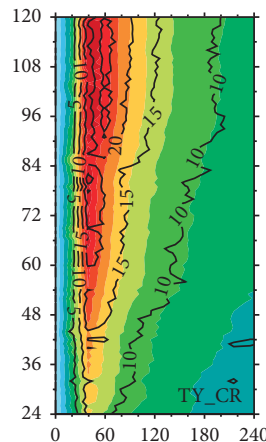

(d)

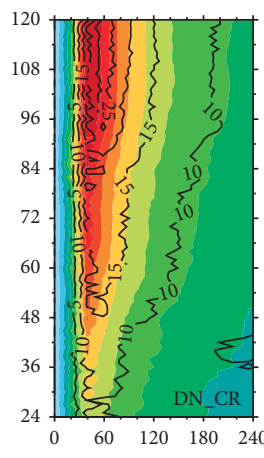

(j)

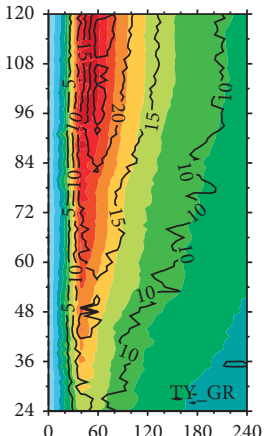

(e)

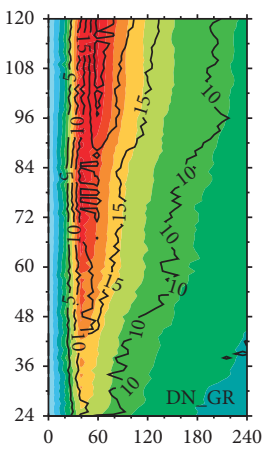

(k)

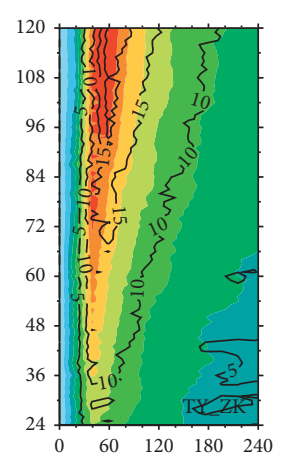

(f)

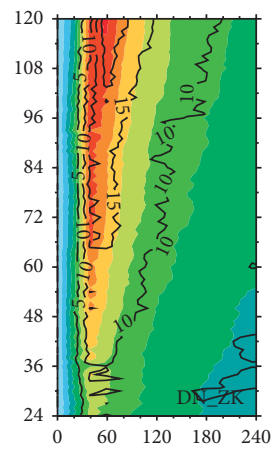

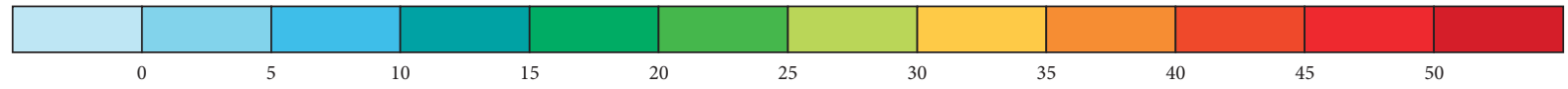

FIGURE 6: Hovmöller diagrams of azimuthally averaged tangential winds (colors, $\mathrm{m} / \mathrm{s}$ ) and radial winds (black lines, $\mathrm{m} / \mathrm{s}$ ) from 12 experiments. $x$-axis denotes the distance $(\mathrm{km})$ from the center of the typhoon and $y$-axis denotes the forecast hours.


(f)

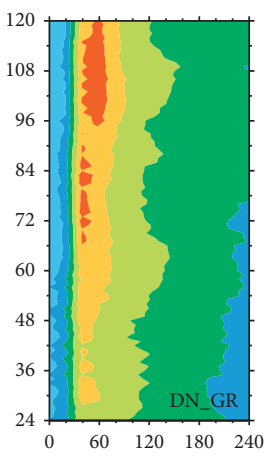

(k)

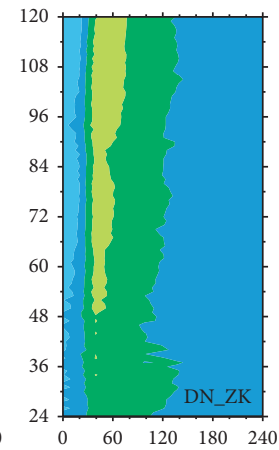

(l)

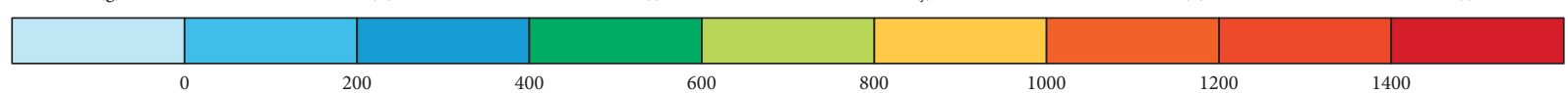

FIGURE 7: Hovmöller diagrams of azimuthally averaged latent heat flux $\left(\mathrm{W} / \mathrm{m}^{2}\right)$ from 12 experiments. $x$-axis denotes the distance $(\mathrm{km})$ from the center of the typhoon and $y$-axis denotes the forecast hours. 


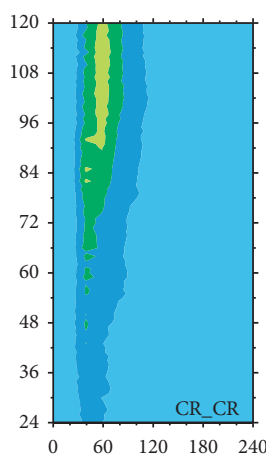

(a)

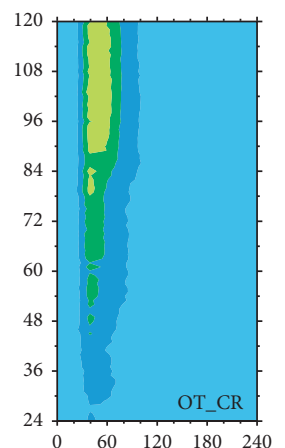

(g)

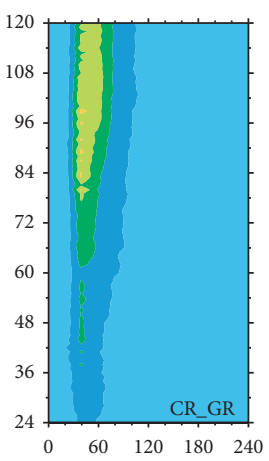

(b)

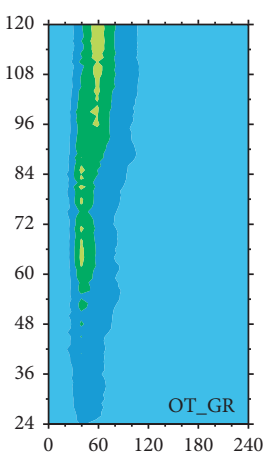

(h)

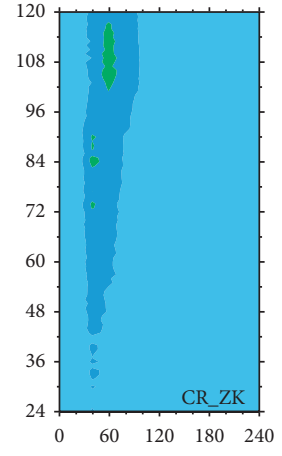

(c)

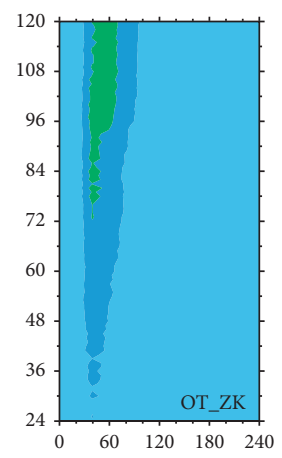

(i)

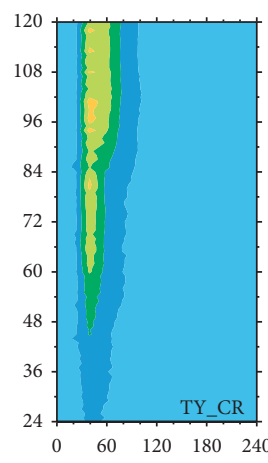

(d)

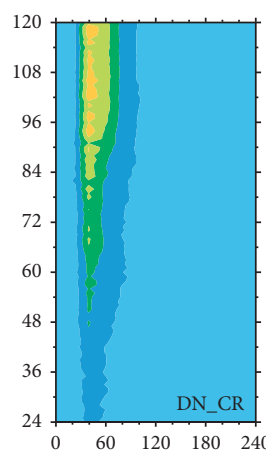

(j)

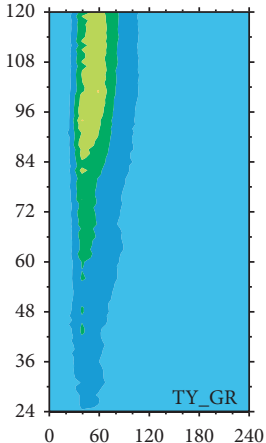

(e)

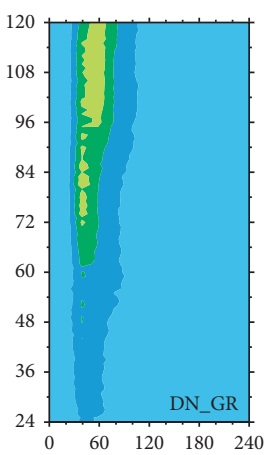

(k)

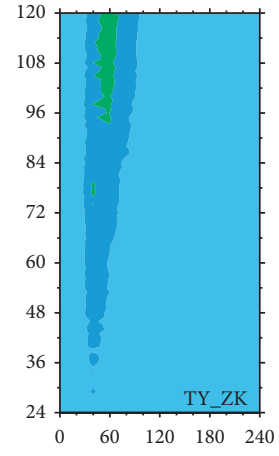

(f)

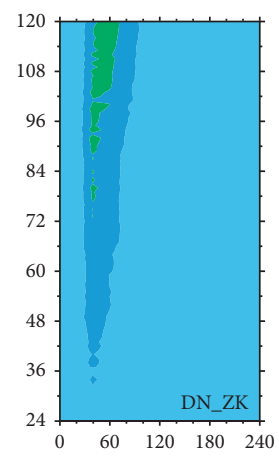

(1)

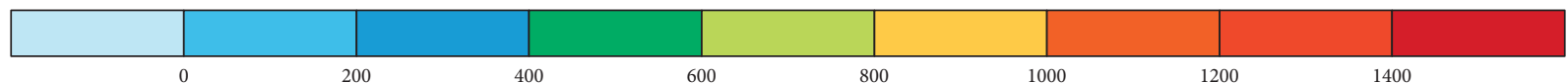

Figure 8: As in Figure 7, but for the azimuthally averaged sensible heat flux $\left(\mathrm{W} / \mathrm{m}^{2}\right)$.

wind field structure of a typhoon is dominated by tangential rotation, accompanied by a weaker convergence effect. The maximum value of radial wind generally appears at a distance of $60 \mathrm{~km}$ from the center, while the maximum value of tangential wind is probably distributed between 40 and $60 \mathrm{~km}$, indicating that the region with strongest convergence effect is slightly outside the region with the strongest rotation effect. This feature has also been presented by Green and Zhang [6] (see Figure 7 therein). From the results of experiments with strong typhoon intensity (CR_GR (Figure 6(b)), TY_CR (Figure 6(d)), TY_GR (Figure 6(e)), OT_CR (Figure $6(\mathrm{~g})$ ), and DN_CR (Figure 6(j)), the maximum tangential wind speed radius at $120 \mathrm{~h}$ is roughly 40-50 km, while for experiments with weaker typhoon intensity (CR_ZK (Figure 6(c)) and DN_ZK (Figure 6(1)), the maximum tangential wind speed radius at $120 \mathrm{~h}$ is about $60 \mathrm{~km}$, indicating that not only the horizontal scale of typhoon, but also the radial distributions of winds are affected by momentum and heat transfer between air and sea.

4.3. Heat Flux at Sea Surface. To determine the causes of differences in typhoon intensity from different experiments, we analysed the heat flux at sea surface simulated by different experiments. Time evolution of azimuthally averaged latent heat flux and sensible heat flux at sea surface is plotted in Figures 7 and 8, respectively. By comparison, heat transported by latent heat flux is stronger than the sensible heat flux. Similar to the distribution of wind speed in Figure 6, the distributions of two heat fluxes both show the characteristics of increasing at first, and then decreasing along the radial direction. Heat transfer in Figures 7 and 8 corresponds to the development of wind field in Figure 6, and typhoon simulated by experiments with stronger heat flux can acquire more energy from the ocean, which lead to the development of wind field. The poor results from ZK scheme in the intensity simulation are caused by the poor results in the calculation of heat flux, which are caused by the unreasonable calculation of $z_{t}$ and $z_{q}$. The enthalpy exchange coefficient calculated by ZK decreases with increasing wind speed (cf Figure 2(b) in Bao et al. [4]), which is not consistent with the consensus that enthalpy exchange coefficient increases or keeps constant with increasing wind speed [64-66].

To verify this result, we plotted the distribution of enthalpy flux (sum of latent heat flux and sensible heat flux) and $10 \mathrm{~m}$ level wind speed at $120 \mathrm{~h}$ (1200 UTC 27 Oct 2018) in Figure 9. It is demonstrated that there is a strong correlation between distributions of wind speed and distributions of enthalpy flux; the contours of wind speed are parallel to the contours of enthalpy flux in general, and the distribution of horizontal gradient of enthalpy flux is consistent with that of wind speed. Based on the strong correlation between enthalpy flux and wind speed, it can be concluded that different heat flux parameterization schemes lead to differences in sea surface heat flux, which in turn has an important impact on the intensity of typhoons. 

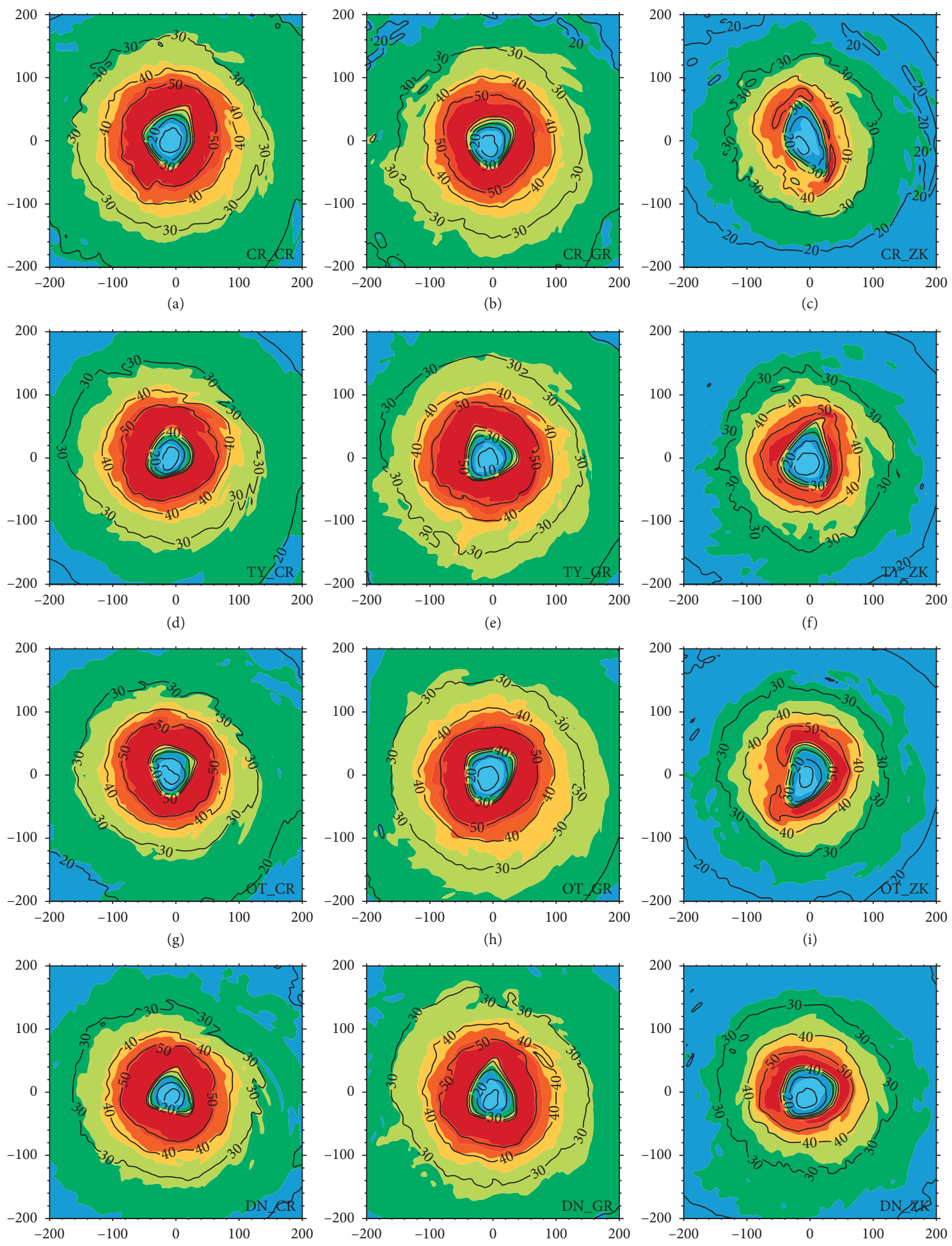

(k)

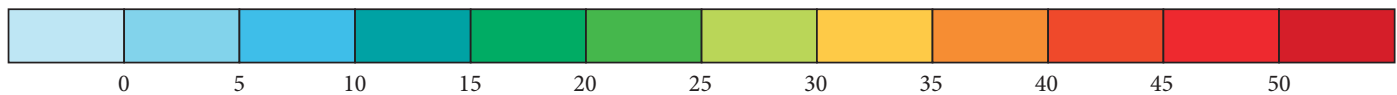

Figure 9: Comparison between enthalpy flux (colors, $\mathrm{W} / \mathrm{m}^{2}$ ) and wind speed at $10 \mathrm{~m}$ level (black lines, $\mathrm{m} / \mathrm{s}$ ) from 12 experiments at 1200 UTC 27 Oct 2018. Axis denotes the distance $(\mathrm{km})$ from the center of the typhoon. 


\section{Conclusions}

It is of great significance to accurately forecast the intensity of tropical cyclones, especially typhoons. Energy transfer between air and sea is crucial for the evolution of typhoon intensity. In this paper, we use the coupling model COAWST to study the impacts of four momentum flux parameterization schemes and three heat flux parameterization schemes on the simulation of Super Typhoon Yutu. From the results, we concluded the following.

(1) Track simulations of Yutu are not sensitive to the flux parameterization schemes. Differences between schemes are mainly presented in the intensity simulations. Among the four momentum flux parameterization schemes, three wave-state-based schemes (TY, OT, and DN) provide better intensity results than the wind-speed-based COARE scheme. This is caused by the different performances of them in parameterization of $z_{0}$. Three wave-state-based schemes (TY, OT, and DN) provide better intensity results than the wind-speed-based COARE scheme because wave state has a nonnegligible impact on the sea surface roughness.

(2) Among the three heat flux parameterization schemes, the results of the GR scheme are slightly better than that of the COARE scheme; both the GR and COARE schemes are significantly better than the $\mathrm{ZK}$ scheme, from which the intensity of Yutu is under predicted obviously. The poor result of $\mathrm{ZK}$ is because it calculates an unreasonable $z_{t}$ and $z_{q}$. The enthalpy exchange coefficient calculated by ZK decreases with increasing wind speed, which is not consistent with the consensus that enthalpy exchange coefficient increases or keeps constant with increasing wind speed.

(3) Differences of intensity between different schemes are related to the simulated sea surface heat flux. Heat transferred at sea surface has a significant impact on the wind field. There is a strong correlation between the distributions of wind speed and distributions of enthalpy flux; area with large enthalpy flux can acquire more energy from the ocean, which leads to the development of wind field.

\section{Data Availability}

The JTWC TC Best-Track data used to support the findings of this study have been deposited in the Joint Typhoon Warning Center website (https://www.metoc.navy.mil/jtwc/ jtwc.html?western-pacific). The NCEP analysis data are obtained from https://rda.ucar.edu/datasets/ds083.3/.

\section{Conflicts of Interest}

The authors declare that they have no conflicts of interest.

\section{Acknowledgments}

This study was supported by the National Key R\&D Program of China (Grant no. 2018YFB0203801) and the National Nature Science Foundation of China (Grant no. 41605070).

\section{References}

[1] X. Lyu, X. Wang, and L. M. Leslie, "The dependence of Northwest Pacific tropical cyclone intensification rates on environmental factors," Advances in Meteorology, vol. 201918 pages, Article ID 9456873, 2019.

[2] T. Hu, B. Liu, D. Wu, and X. Yi, "Analysis of the gale in the bohai sea caused by tropical cyclone Yagi," Advances in Meteorology, vol. 2019, Article ID 1853797, 15 pages, 2019.

[3] Y. Chen, F. Zhang, B. W. Green, and X. Yu, "Impacts of ocean cooling and reduced wind drag on Hurricane Katrina (2005) based on numerical simulations," Monthly Weather Review, vol. 146, no. 1, pp. 287-306, 2018.

[4] J.-W. Bao, S. A. Michelson, and J. M. Wilczak, "Sensitivity of numerical simulations to parameterizations of roughness for surface heat fluxes at high winds over the sea," Monthly Weather Review, vol. 130, no. 7, pp. 1926-1932, 2002.

[5] G. H. Bryan, "Effects of surface exchange coefficients and turbulence length scales on the intensity and structure of numerically simulated hurricanes," Monthly Weather Review, vol. 140, no. 4, pp. 1125-1143, 2012.

[6] B. W. Green and F. Zhang, "Impacts of air-sea flux parameterizations on the intensity and structure of tropical cyclones," Monthly Weather Review, vol. 141, no. 7, pp. 2308-2324, 2013.

[7] S. Liu, J. Li, L. Sun et al., "Basin-wide responses of the south China sea environment to super typhoon mangkhut (2018)," Science of The Total Environment, vol. 731, Article ID 139093, 2020.

[8] S. D. Smith, R. J. Anderson, W. A. Oost et al., "Sea surface wind stress and drag coefficients: the HEXOS results," Boundary-Layer Meteorology, vol. 60, no. 1-2, pp. 109-142, 1992.

[9] G. L. Geernaert, S. E. Larsen, and F. Hansen, "Measurements of the wind stress, heat flux, and turbulence intensity during storm conditions over the North Sea," Journal of Geophysical Research, vol. 92, no. C12, pp. 13127-13139, 1987.

[10] J. B. Edson, V. Jampana, R. A. Weller et al., "On the exchange of momentum over the open ocean," Journal of Physical Oceanography, vol. 43, no. 8, pp. 1589-1610, 2013.

[11] B. Liu, C. Guan, and L. Xie, "The wave state and sea spray related parameterization of wind stress applicable from low to extreme winds," Journal of Geophysical Research: Oceans, vol. 117, no. C11, 2012.

[12] D. Zhao and M. Li, "Dependence of wind stress across an air-sea interface on wave states," Journal of Oceanography, vol. 75, no. 3, pp. 207-223, 2019.

[13] J. Kondo, "Air-sea bulk transfer coefficients in diabatic conditions," Boundary-Layer Meteorology, vol. 9, no. 1, pp. 91-112, 1975.

[14] J. Wu, "Wind-Stress coefficients over sea surface near neutral conditions-A revisit," Journal of Physical Oceanography, vol. 10, no. 5, pp. 727-740, 1980. 
[15] W. G. Large and S. Pond, "Open ocean momentum flux measurements in moderate to strong winds," Journal of Physical Oceanography, vol. 11, no. 3, pp. 324-336, 1981.

[16] M. A. Donelan, "The dependence of the aerodynamic drag coefficient on wave parameters," in Proceedings of First International Conference on Meteorology and Air-Sea Interaction of the Coastal Zone, pp. 381-387, Hague, Netherlands, May 1982.

[17] D. Vickers and L. Mahrt, "Fetch limited drag coefficients," Boundary-Layer Meteorology, vol. 85, no. 1, pp. 53-79, 1997.

[18] W. M. Drennan, H. C. Graber, and M. A. Donelan, "Evidence for the effects of swell and unsteady winds on marine wind stress," Journal of Physical Oceanography, vol. 29, no. 8, pp. 1853-1864, 1999.

[19] C. Guan and L. Xie, "On the linear parameterization of drag coefficient over sea surface," Journal of Physical Oceanography, vol. 34, no. 12, pp. 2847-2851, 2004.

[20] A. Toffoli, L. Loffredo, P. Le Roy, J.-M. Lefèvre, and A. Babanin, "On the variability of sea drag in finite water depth," Journal of Geophysical Research: Oceans, vol. 117, no. C11, 2012.

[21] M. A. Bender, I. Ginis, and Y. Kurihara, "Numerical simulations of tropical cyclone-ocean interaction with a high-resolution coupled model," Journal of Geophysical Research, vol. 98, no. D12, pp. 23245-23263, 1993.

[22] H. L. Tolman, B. Balasubramaniyan, L. D. Burroughs et al., "Development and implementation of wind-generated ocean surface wave modelsat NCEP," Weather and Forecasting, vol. 17, no. 2, pp. 311-333, 2002.

[23] M. Donelan, B. K. Haus, N. Reul et al., "On the limiting aerodynamic roughness of the ocean in very strong winds," Geophysical Research Letters, vol. 31, no. 18, 2004.

[24] N. Takagaki, S. Komori, N. Suzuki et al., "Strong correlation between the drag coefficient and the shape of the wind sea spectrum over a broad range of wind speeds," Geophysical Research Letters, vol. 39, no. 23, 2012.

[25] M. D. Powell, P. J. Vickery, and T. A. Reinhold, "Reduced drag coefficient for high wind speeds in tropical cyclones," Nature, vol. 422, no. 6929, pp. 279-283, 2003.

[26] Y. Troitskaya, E. Ezhova, I. Soustova, and S. Zilitinkevich, "On the effect of sea spray on the aerodynamic surface drag under severe winds," Ocean Dynamics, vol. 66, no. 5, pp. 659-669, 2016.

[27] S. Komori, K. Iwano, N. Takagaki et al., "Laboratory measurements of heat transfer and drag coefficients at extremely high wind speeds," Journal of Physical Oceanography, vol. 48, no. 4, pp. 959-974, 2018.

[28] P. K. Taylor and M. J. Yelland, "The dependence of sea surface roughness on the height and steepness of the waves," Journal of Physical Oceanography, vol. 31, no. 2, pp. 572-590, 2001.

[29] W. M. Drennan, H. C. Graber, D. Hauser, and C. Quentin, "On the wave age dependence of wind stress over pure wind seas," Journal of Geophysical Research: Oceans, vol. 108, no. C3, 2003.

[30] Z. Ma, J. Fei, X. Huang, X. Cheng, and L. Liu, "A study of the interaction between typhoon francisco (2013) and a cold-core eddy. part ii: boundary layer structures," Journal of the Atmospheric Sciences, vol. 77, no. 8, pp. 2865-2883, 2020.

[31] Y. Zhang, Z. Zhang, D. Chen, B. Qiu, and W. Wang, "Strengthening of the kuroshio current by intensifying tropical cyclones," Science, vol. 368, no. 6494, pp. 988-993, 2020.

[32] J. DeCosmo, K. B. Katsaros, S. D. Smith et al., "Air-sea exchange of water vapor and sensible heat: the Humidity
Exchange over the Sea (HEXOS) results," Journal of Geophysical Research: Oceans, vol. 101, no. C5, pp. 12001-12016, 1996.

[33] V. Bharti, C. W. Fairall, B. W. Blomquist et al., "Air-sea heat and momentum fluxes in the southern ocean," Journal of Geophysical Research: Atmospheres, vol. 124, no. 23, pp. 12426-12443, 2019.

[34] S. S. Zilitinkevich, A. A. Grachev, and C. W. Fairall, "NOTES and CORRESPONDECEScaling reasoning and field data on the sea surface roughness lengths for scalars," Journal of the Atmospheric Sciences, vol. 58, no. 3, pp. 320-325, 2001.

[35] P. J. Webster and R. Lukas, "TOGA COARE: Toga COARE: the Coupled Ocean-atmosphere Response experiment," Bulletin of the American Meteorological Society, vol. 73, no. 9, pp. 1377-1416, 1992.

[36] A. B. Villas Boas, F. Ardhuin, A. Ayet et al., "Integrated observations and modeling of global winds, currents, and waves: requirements and challenges for the next decade," Frontiers in Marine Science, vol. 6, p. 425, 2019.

[37] A. Yool, J. Palmiéri, C. Jones et al., "Spin-up of UK earth system model 1 (UKESM1) for CMIP6," Journal of Advances in Modeling Earth Systems, vol. 12, no. 8, p. e2019MS001933, 2020.

[38] H. Charnock, "Wind stress on a water surface," Quarterly Journal of the Royal Meteorological Society, vol. 81, no. 350, pp. 639-640, 1955.

[39] S. D. Smith, K. B. Katsaros, W. A. Oost, and P. G. Mestayer, "Two major experiments in the humidity exchange over the sea (HEXOS) program," Bulletin of the American Meteorological Society, vol. 71, no. 2, pp. 161-172, 1990.

[40] L. Mahrt, D. Vickers, J. Howell et al., "sea surface drag coefficients in the Risø Air Sea experiment," Journal of Geophysical Research: Oceans, vol. 101, no. C6, pp. 14327-14335, 1996.

[41] F. Anctil and M. A. Donelan, "Air-water momentum flux observations over shoaling waves," Journal of Physical Oceanography, vol. 26, no. 7, pp. 1344-1353, 1996.

[42] W. A. Oost, G. J. Komen, C. M. J. Jacobs, and C. Van Oort, "New evidence for a relation between wind stress and wave age from measurements during ASGAMAGE," BoundaryLayer Meteorology, vol. 103, no. 3, pp. 409-438, 2002.

[43] M. Donelan and W. Drennan, "Direct field measurements of the flux of carbon dioxide," Air-Water Gas Transfer, vol. 677, p. $683,1995$.

[44] D. Hauser, H. Branger, S. Bouffies-Cloché et al., "The FETCH experiment: an overview," Journal of Geophysical Research: Oceans, vol. 108, no. C3, 2003.

[45] M. A. Donelan, W. M. Drennan, and K. B. Katsaros, "The air-sea momentum flux in conditions of wind sea and swell," Journal of Physical Oceanography, vol. 27, no. 10, pp. 2087-2099, 1997.

[46] M. A. Donelan, N. Madsen, K. K. Kahma, I. K. Tsanis, and W. M. Drennan, "Apparatus for atmospheric surface layer measurements over waves," Journal of Atmospheric and Oceanic Technology, vol. 16, no. 9, pp. 1172-1182, 1999.

[47] J. R. Garratt, "The atmospheric boundary layer," Earth-Science Reviews, vol. 37, no. 1-2, pp. 89-134, 1994.

[48] C. W. Fairall, A. B. White, J. B. Edson, and J. E. Hare, "Integrated shipboard measurements of the marine boundary layer," Journal of Atmospheric and Oceanic Technology, vol. 14, no. 3, pp. 338-359, 1997.

[49] J. C. Warner, B. Armstrong, R. He, and J. B. Zambon, "Development of a Coupled Ocean-Atmosphere-Wave-Sediment transport (COAWST) modeling system," Ocean Modelling, vol. 35, no. 3, pp. 230-244, 2010. 
[50] Z. Liwei and Z. Tianjun, "A review of development and application of regional ocean-atmosphere coupled model," Advances in Earth Science, vol. 27, no. 8, pp. 857-865, 2012.

[51] S.-H. Chen and W.-Y. Sun, "A one-dimensional time dependent cloud model," Journal of the Meteorological Society of Japan. Ser. II, vol. 80, no. 1, pp. 99-118, 2002.

[52] M. J. Iacono, J. S. Delamere, E. J. Mlawer et al., "Radiative forcing by long-lived greenhouse gases: calculations with the AER radiative transfer models," Journal of Geophysical Research: Atmospheres, vol. 113, no. D13, 2008.

[53] M. Nakanishi and H. Niino, "Development of an improved turbulence closure model for the atmospheric boundary layer," Journal of the Meteorological Society of Japan, vol. 87, no. 5, pp. 895-912, 2009.

[54] M. Ek, K. Mitchell, Y. Lin et al., "Implementation of Noah land surface model advances in the National Centers for Environmental Prediction operational mesoscale Eta model," Journal of Geophysical Research: Atmospheres, vol. 108, no. D22, 2003.

[55] J. S. Kain, "The kain-fritsch convective parameterization: an update," Journal of Applied Meteorology, vol. 43, no. 1, pp. 170-181, 2004.

[56] M. Olabarrieta, J. C. Warner, B. Armstrong, J. B. Zambon, and R. He, "Ocean-atmosphere dynamics during Hurricane Ida and Nor'Ida: an application of the coupled ocean-atmosphere-wave-sediment transport (COAWST) modeling system," Ocean Modelling, vol. 43-44, pp. 112-137, 2012.

[57] J. Song, Y. Duan, and P. J. Klotzbach, "Increasing trend in rapid intensification magnitude of tropical cyclones over the western North Pacific," Environmental Research Letters, vol. 15, no. 8, p. 084043, 2020.

[58] H. Chen and D.-L. Zhang, "On the rapid intensification of hurricane wilma (2005). part ii: convective bursts and the upper-level warm core," Journal of the Atmospheric Sciences, vol. 70, no. 1, pp. 146-162, 2013.

[59] X. Tang, F. Ping, S. Yang, M. Li, and J. Peng, "Relationship between convective bursts and the rapid intensification of typhoon mujigae (2015)," Atmospheric Science Letters, vol. 19, no. 4, p. e811, 2018.

[60] X. Chen, Y. Yao, S. Zhao et al., "Estimation of high-resolution global monthly ocean latent heat flux from MODIS SST product and AMSR-E data," Advances in Meteorology, vol. 2020, Article ID 8857618, 19 pages, 2020.

[61] M. Golbazi and C. L. Archer, "Methods to estimate surface roughness length for offshore wind energy," Advances in Meteorology, vol. 2019, Article ID 5695481, 15 pages, 2019.

[62] W. M. Drennan, P. K. Taylor, and M. J. Yelland, "Parameterizing the sea surface roughness," Journal of Physical Oceanography, vol. 35, no. 5, pp. 835-848, 2005.

[63] K. R. Prakash, V. Pant, and T. Nigam, "Effects of the sea surface roughness and sea spray-induced flux parameterization on the simulations of a tropical cyclone," Journal of Geophysical Research: Atmospheres, vol. 124, no. 24, pp. 14037-14058, 2019.

[64] C. A. Friehe and K. F. Schmitt, "Parameterization of air-sea interface fluxes of sensible heat and moisture by the bulk aerodynamic formulas," Journal of Physical Oceanography, vol. 6, no. 6, pp. 801-809, 1976.

[65] D. B. Ross and V. Cardone, "Observations of oceanic whitecaps and their relation to remote measurements of surface wind speed," Journal of Geophysical Research, vol. 79, no. 3, pp. 444-452, 1974.
[66] G. L. Geernaert, K. B. Katsaros, and K. Richter, "Variation of the drag coefficient and its dependence on sea state," Journal of Geophysical Research, vol. 91, no. C6, pp. 7667-7679, 1986. 